\title{
Zu ne. hair.
}

Oben s. 286 habe ich gesagt, das auftreten von hair für me. hẹr bediirfe noch der aufhellung. Nunmehr glaube ich eine erklärung geben zu können, die freilich vielleicht vielen nichts neues ist, obwohl sie, so viel ich sehe, noch nirgends ausgesprochen worden.

Es gibt im mittelenglischen ein haire 'haartuch, härenes gewand, cilicium', klärlich aus afr. haire, welches dem einheimischen hëre aus ae. hoere zur seite tritt. Die frühesten belege sind wol haire Old Engl. Hom. II (E. E. T. S. 53) $127^{29}$ und haiyre Gen. Ex. 1977. Daneben hält sich das heimische wort; noch bei Wyclif findet sich einmal heer gegenüber gewöhnlichem heir hair (Gasner, Beiträge zum Entwicklungsgang der neuengl. Schriftsprache s. 117).

Aus der vermengung dieses wortes mit hẹr (ae. huer $r)$ scheint mir nun das ne. hair hervorgegangen zu sein. Das Mittelenglische zwar hielt die begrifflich und lautlich einander nahestehenden worte nach den belegen bei Mätzner noch geschieden. Hampole's haire ist die bekannte nördliche schreibung für har; auch heir Alis. 6495 und haire Seuyn Sag. 121 sind nicht beweisend, denn in beiden denkmälern finden sich nördliche schreibungen. (Seuyn Sag: blayke 121; Alis: yeild 2015, 2067, steil 2303, 3153, 3212, Peirce 2318, scheip 2420). Das Catholicon Anglicum bietet heire 'pilus' s. 180, heyre 'crinis' 184 gegeniiber haire 'cilicium' 170; aber auch hier steht $e i$ (ey) öfter für $\bar{e}$ : heille 'calcaneus, calx' 180, fley 'pulex' 134, to leyde 'ducere' 212, leyn (lene A) 'exilis' 214 etc.

Dagegen bat am ausgang des XV. jahrhunderts Caxton neben gewöhnlichem here heere mindestens einmal heyr in der bedeutung 'haar', Eneydos 15,7 (E. E. T.S. Extra S. 57), während er sonst $i$ und ay ey streng auseinander hält. Die anderen fälle diphthongischer schreibung, welche Römstedt, Die englische Schriftsprache bei Caxton s. 4, antührt, kommen nicht in betracht. Wie mir Prof. Brandl mitteilt, welcher die giite hatte, fiir mich in Sommers neudruck von Caxtons Morte Darthur die betreffenden stellen nachzuschlagen, ist M. A. 2727 und 65716 haire = cilicium; 36219 heisst es: the lady of the lake took up her heed and henge it up by the heyre of her sadel bowe; es ist also wol auch eine art cilicium gemeint. Im XVI. jahrhundert finden wir bei Tindale, wie es scheint, nur die $\bar{e}$-form (Sopp, Angl. XII, 291), ebenso bei Surrey (Salge, Vocalismus bei Surrey s. 13). Vicary's Anatomie, 1577 von den wundïrzten des Bartholomäusspitals herausgegeben (E.E.S. T. Extra S. 53), zeigt dagegen durchaus heyr (s. $43 \mathrm{ff}$.). Spenser bietet in entsprechenden reimen einerseits heare F.Q.14, 24 ; II 9, 13, andrerseits haire I 5, 2; IV 11, 48. Shakespeare schreibt in Venus and Adonis und Lucrece einige male $e a$ (Würzner s. 5), während die folio vom jahre 1623 durchaus hair aufweist. Im reim erscheint das wort drei mal mit altem ai gebunden (Ellis III 95i). Ein wortspiel zwischen hair und heir Com. Err. 3, 2, 41 weist ebenfalls, freilich nicht zwingend, auf diphthongische lautung (ib. 924). Seit dem beginn des XVII. jahrhunderts scheint die form hair festzustehen. 
Von den grammatikerzeugnissen des XVI. jahrhunderts bietet Bullokar die für me. $\ddot{z}$ zu erwartende lautung; Cheke's transcription ist nicht klar, jedenfalls aber meint er nicht den diphthong ai (Ellis III 893). Dagegen bietet eine französische grammatik aus dem jahre 1595 (Kluge in Paul's Grdr. I 876) bereits die form hair und hier findet sich zum ersten mal die gleichstellung von hair und hare. Bei den englischen gewährsmännern tritt sie uns zuerst entgegen bei Hodges (1643), der auch pare und pair, race und raise gleichstellt (Ellis IV 1020). Das sind also vertreter der forschrittlichen richtung (vgl. oben $276 \mathrm{ff}$.), denen die volkstümliche monophthongierung des $a i$ zu $\bar{a}$ schon geläufig ist, obwol Hodges an anderer stelle (Ellis IV, 1023) ay unter den diphthongen anführt. Dieselbe gleichung bietet Price 1668 (ib. 1020) und Cooper 1685 (ib. 1030), der auch in seinen transcriptionen in diesem wort denselben laut zeigt wie sonst für ai und $\bar{a}$ (ib. 1009).

Damit entfallen alle combinationen, welche Lummert an das auf kommen der form hair geknüpft hat.

Graz, am 5. December 1891.

KARL LUICK.

\section{ZU "ALL'S WELL THAT ENDS WELL".}

K. Elze bekennt sich in einem auf Gisbert freiherrn Vincke's theaterbearbeitung von "Ende gut, alles gut" bezüglichen sendschreiben' ehrlich zu der ansicht, dass die verïnderte anschaungsweise der zeitalter in bezug auf das verhältniss der geschlechter der alleinige grund des interessemangels und abfälligen urteils der gegenwart über jenes drama sei, und verficht diese ansicht mit stichhaltigen gründen. Es wirkt besonders der umstand, dass ein mädchen sich verkleidet an die fersen des sie verschmähenden liebhabers heftet und mit mitteln, die dem modernen, 'guten tone' unlauter ausschen, ihn meist schliesslich für sich einfängt. Die mittelalterliche litteratur liefert eine grosse anzahl von beispielen hierfür, und ich gestatte mir, der kürze halber auf einige aus anderem zwecke von mir zusammengetragene hinzuweisen. ${ }^{2}$

Gerade einer der an schürfsten als frivol gebrandmarkten Dialoge des stiicks zeigt recht deutlich Shakespeare's kiinstlerische tendenz darin, den gegensatz des ernsten und heitern, das wechselverhältniss dieser beiden stimmungen ${ }^{5}$ : der zweite teil des 1 . aluftritts von akt $1 . *$ Die höhe

1 Abhandlungen zu Shakespeare, s. $252 \mathrm{ff}$. (besonders s. $252 \mathrm{f}$., u. s. 256 f.). Etwas "romantisch und bizarr" (Dr. Timon, Shakespeare's Drama, 1889 , s. 414) bleibt Helena's vorgehen allerdings trotzdem auch fiir den modernen realisten.

2 Ztschr. f. vergleichd. Literaturgesch., N. F. IV, $79 \mathrm{ff}$.

${ }^{3}$ Das auch in dem tausch von prosa und blankvers zum ausdruck kommt: vgl. Delius, Abhandlungen zu Shakspere I, s. 165.

- Hier erblicke ich auch in den versen $I, 1,140$ ff. einen bisher übersehenen beley fiir die annahrne, dass das von Francis Meres 1598 "Love's labour's won" genannte drama Shakespeare's mit "Ende gut, alles gut" identisch ist. 